\title{
Sporulation of Several Species of Streptomyces in Submerged Cultures after Nutritional Downshift
}

\author{
By ANTONIO DAZA, ${ }^{1}$ JUAN F. MARTÍN, ${ }^{1 *}$ ANGEL DOMINGUEZ ${ }^{2}$ AND \\ JOSÉ A. GIL \\ ${ }^{1}$ Departamento de Microbiología, Facultad de Biología, Universidad de León, León, Spain \\ ${ }^{2}$ Departamento de Microbiología, Facultad de Biología, Universidad de Salamanca, \\ Salamanca, Spain
}

(Received 13 March 1989; revised 18 May 1989; accepted 9 June 1989)

\begin{abstract}
Streptomyces griseus ATCC 10137, S. griseus IMRU 3570, S. griseus JI 2212, S. acrimycini JI 2236 and $S$. albus G sporulated abundantly in several liquid media after nutritional downshift. Spores formed in submerged cultures were viable and as thermoresistant as aerial spores. Scanning electron microscopy showed that submerged spores are morphologically similar to aerial spores. The sporulation of the Streptomyces strains tested in complex medium appeared to be triggered by phosphate nutritional downshift, induced by addition of $\mathrm{Ca}^{2+}$ to the medium. Spore-shaped bodies were formed by S. lividans JI 1326 and S. coelicolor JI 2280 when grown in complex medium supplemented with $\mathrm{Ca}^{2+}$ and proline. The thermoresistance of these spore-shaped bodies differed from that of aerial spores.
\end{abstract}

\section{INTRODUCTION}

Members of the genus Streptomyces are Gram-positive bacteria with an unusual morphological complexity. On solid medium a spore germinates, grows vegetatively as a substrate mycelium and then develops into an aerial mycelium, which segments into chains of spores (Ensign, 1978; Chater, 1984).

The ultrastructural changes occurring during sporulation of Streptomyces on solid media have been studied in detail (Hopwood et al., 1970; Wildermuth \& Hopwood, 1970; Hardisson \& Manzanal, 1976). However, physiological studies on the molecular control of differentiation have been hampered by the inability to obtain uniform sporulation of Streptomyces in liquid cultures. There are a few examples of Streptomyces species which sporulate in liquid cultures (Kendrick \& Ensign, 1983; Koepsel \& Ensign, 1984). The possible use of these strains for cloning and expression of sporulation genes is of great interest and the study of gene expression during sporulation would be greatly simplified if adequate conditions for abundant sporulation in liquid media of other species of Streptomyces could be established. Moreover, in liquid cultures the differential gene expression that triggers the cascade of events leading to spore formation may be correlated with the mechanisms that control gene expression during antibiotic biosynthesis.

We describe in this paper the culture conditions used to obtain uniform or abundant sporulation of five Streptomyces strains. These techniques should enable analysis of sporulation specific mRNAs or the formation of spore proteins during sporulation in liquid cultures.

\section{METHODS}

Streptomyces strains. The strains used in this work and their phenotypes are listed in Table 1.

Media and culture conditions. All the Streptomyces strains were grown on solid R2YE medium (Thompson et al., 1980), minimal medium (MM) (Hopwood, 1967) or YED medium (Gil et al., 1985). Aerial spores were prepared as described by Hopwood et al. (1985). Stock cultures were maintained as spore suspensions in $20 \%(\mathrm{v} / \mathrm{v}) \mathrm{glycerol}$ at $-20^{\circ} \mathrm{C}$. 
Table 1. Streptomyces strains used

\begin{tabular}{lll}
\multicolumn{1}{c}{ Strain } & Phenotype/genotype & Source* \\
S. griseus ATCC 10137 & Wild-type & ATCC \\
S. griseus JI 2212 & Wild-type & JI \\
S. griseus IMRU 3570 & Wild-type & IMRU \\
S. lividans JI 1326 & Wild-type & JI \\
S. acrimycini JI 2236 & Wild-type & JI \\
S. coelicolor JI 2280 & cysE24 pabAI str-1 & JI \\
S. clavuligerus NRRL 3585 & Wild-type & NRRL \\
S. lactamdurans NRRL 3802 & Wild-type & NRRL \\
S. albus G & Wild-type & JI \\
S. fradiae ATCC 10745 & Wild-type & ATCC
\end{tabular}

* ATCC, American Type Culture Collection; JI, Collection of micro-organisms of the John Innes Institute, Colney Lane, Norwich NR4 7UH, UK; IMRU, Waksmans Institute of Microbiology, Rutgers University, New Brunswick, NJ, USA; NRRL, Northern Regional Research Laboratories, Peoria, Illinois, USA.

Formation of spores in submerged cultures. Spores from submerged cultures were obtained by inoculating seed cultures (liquid R2YE or YED media) with $10^{9}$ spores in 250 ml triple baffled flasks or $250 \mathrm{ml}$ coiled spring flasks containing $50 \mathrm{ml}$ of YED or R2YE. The cultures were incubated at $30^{\circ} \mathrm{C}$ in a rotary shaker at 220 r.p.m. for 24-30 $\mathrm{h}$. Seed culture $(1 \mathrm{ml}$ ) was inoculated into $50 \mathrm{ml}$ of sporulation medium (liquid $\mathrm{MM}$ with supplements, when required for auxotrophic strains) and incubated for $2-6 \mathrm{~d}$ in a rotary shaker at $30^{\circ} \mathrm{C}$. Alternatively, spores from submerged cultures were also obtained in liquid R2YE without transfer to MM. Submerged spores were prepared from the culture media by filtration through a cotton filter and stored in $20 \%$ glycerol at $-20^{\circ} \mathrm{C}$. In some experiments, the composition of the liquid R2YE, YED or MM was modified as described in Results.

Resistance to moist heat. Heat resistance tests were carried out by heating aerial spores, submerged spores and vegetative mycelia at $55^{\circ} \mathrm{C}$ for different times $(2,5,10,30$ and $60 \mathrm{~min})$. After heating, the colony-forming units (c.f.u.) $\mathrm{ml}^{-1}$ were counted by plating on YED or R2YE media. After $5,10,30$ and 60 min heating at $55^{\circ} \mathrm{C}$, all of the vegetative mycelia of $S$. griseus were killed whereas $99 \%, 80 \%, 62 \%$ and $57 \%$ of the aerial spores and $100 \%$, $99 \%, 96 \%$ and $90 \%$ of the submerged spores, respectively, survived this treatment. The mycelia and spore-shaped bodies of S. lividans and $S$. coelicolor were completely killed after $10 \mathrm{~min}$ heating at $55^{\circ} \mathrm{C}$, whereas $87 \%$ and $63 \%$ of the aerial spores, respectively, survived this treatment.

Determination of sporulation efficiency. Because spores, but not mycelia, were resistant to sonication, we calculated the fraction of cells that became spores in old cultures $(144 \mathrm{~h})$, when mycelia were highly fragmented, as (c.f.u. $\mathrm{ml}^{-1}$ after $3 \mathrm{~min}$ of sonication)/(c.f.u. $\mathrm{ml}^{-1}$ in the absence of sonication $\times$ factor of mycelium fragmentation). The mean number of cells or spores per fragment was determined by microscopic observations, assuming a mean cell or spore size of $1.75 \mu \mathrm{m}$.

Since spores, but not mycelia, were thermoresistant we estimated the development of the sporulation process in the whole culture by determining the ratio of c.f.u. $\mathrm{ml}^{-1}$ with and without heating for $30 \mathrm{~min}$ at $55^{\circ} \mathrm{C}$. Before the heat treatment the whole culture was sonicated, when required, to give a mean hyphal length of $15 \mu \mathrm{m}$. The number of c.f.u. shown in Results is a mean of four independent experiments.

Scanning electron microscopy. The sporulated submerged cultures of different Streptomyces were centrifuged, washed in $100 \mathrm{mM}$-sodium phosphate buffer, $\mathrm{pH} 7 \cdot 4$, prefixed with glutaraldehyde $\left(50 \mathrm{~g}^{-1}\right)$ in $100 \mathrm{mM}$-phosphate buffer and placed in osmium tetroxide $\left(10 \mathrm{~g} \mathrm{l}^{-1}\right)$ for $1 \mathrm{~h}$ at $4^{\circ} \mathrm{C}$ (Luengo et al., 1986). The material was subsequently washed in distilled water and dehydrated in a graded acetone series. The dehydrated cells, immersed in absolute acetone, were mounted on specimen holders, and were air-dried, coated with gold in a Polaron 5000, and examined in a Philips PSEM 500 scanning electron microscope.

\section{RESULTS}

\section{Sporulation after nutritional downshift}

Spores, but not mycelia, from all the strains tested were resistant to sonication $(>90 \%$ of spores survived 4 min sonication, whereas mycelia were completely killed after 2 min sonication), as reported by Kendrick \& Ensign (1983) for S. griseus B-2682. Sonication treatment was therefore used to differentiate submerged spores from mycelia and to estimate the sporulation efficiency.

Results from studies using ten Streptomyces strains grown in different culture conditions indicated that $S$. griseus ATCC 10137, S. griseus IMRU 3570, S. griseus JI 2212, S. albus G and 


\section{Table 2. Sporulation efficiencies of different Streptomyces strains}

Sporulation efficiencies were determined after $144 \mathrm{~h}$ of growth in liquid MM + TES buffer ( $25 \mathrm{mM}$, $\mathrm{pH} \mathrm{7-2)}$ after nutritional downshift from liquid YED. The cell + spore titres were estimated as (c.f.u. $\mathrm{ml}^{-1}$ without sonication) $\times$ (number of cells or spores per mean fragment). The spore titres were calculated as c.f.u. $\mathrm{ml}^{-1}$ after 3 min sonication. Similar results were observed when the Streptomyces strains were grown in liquid R2YE.

\begin{tabular}{lccc}
\multicolumn{1}{c}{ Strain } & $\begin{array}{c}\text { Cell + spore } \\
\text { titre }\end{array}$ & Spore titre & $\begin{array}{c}\text { Sporulation } \\
\text { efficiency } \\
(\%)\end{array}$ \\
S. griseus ATCC 10137 & $5.4 \times 10^{10}$ & $5.3 \times 10^{10}$ & 98 \\
S. griseus JI 2212 & $3.8 \times 10^{10}$ & $3.7 \times 10^{10}$ & 97 \\
S. albus G & $5.1 \times 10^{10}$ & $4 \cdot 7 \times 10^{10}$ & 92 \\
S. acrimycini JI 2236 & $6.2 \times 10^{10}$ & $4.0 \times 10^{10}$ & 64.5 \\
S. griseus IMRU 3570 & $5.3 \times 10^{10}$ & $4.1 \times 10^{10}$ & 77
\end{tabular}

S. acrimycini JI 2236 sporulated abundantly when the inoculum was incubated in YED for $24 \mathrm{~h}$ and then transferred $(1 \mathrm{ml})$ to $50 \mathrm{ml}$ of MM. After 4-6 d of growth, depending on the strain, in MM or MM supplemented with TES buffer (25-50 mM, pH 7.2), about $65-100 \%$ of the cells in liquid cultures became spores (Table 2). Sporulation in liquid $\mathbf{M M}$ was clearly stimulated by $10-15 \%$ following addition of TES buffer $(25-50 \mathrm{mM}, \mathrm{pH} 7 \cdot 2)$ to MM, especially with cultures of $S$. griseus IMRU 3570 and $S$. acrimycini JI 2236. There was no increase in sporulation when MOPS buffer (25-50 mM, pH 7.2) was used, whereas Tris and phosphate buffers (25-50 mM, pH 7.2), reduced the sporulation efficiency. In addition, no clear stimulatory effect was found when L-asparagine was substituted by L-arginine in MM.

Sporulation was not significantly affected by varying the amount of YED culture used to inoculate the liquid MM. However, sporulation in liquid MM decreased by $30-40 \%$ when an old inoculum ( $4 \mathrm{~d}$ or more) in liquid YED was used. Preincubation of all Streptomyces strains in liquid LB (Miller, 1972), TSB (Difco) or YEME (Hopwood et al., 1985) media prevented or reduced induction of sporulation when the culture was transferred to liquid MM.

Only $S$. griseus ATCC 10137 and $S$. griseus IMRU 3570 were able to sporulate in liquid MM + TES buffer (25 mM, pH 7.2) without preincubation in complex YED medium. However, under these conditions, the sporulation was sparse and slow (only 5-10\% of the cells became spores after $7 \mathrm{~d}$ of culture). These results suggested that sporulation is better induced by a nutritional downshift from a rich medium, and occurs poorly when MM is inoculated directly from a spore suspension.

\section{Sporulation in complex $R 2 Y E$ medium}

Surprisingly, S. griseus JI 2212, S. griseus ATCC 10137 and $S$. albus G sporulated almost uniformly ( $>95 \%$ ) in liquid R2YE after $70-80 \mathrm{~h}$ of growth, without changing the medium to produce a nutritional downshift. $S$. griseus IMRU 3570 and $S$. acrimycini JI 2236 were also able to sporulate abundantly ( $>70 \%$ ) in liquid R2YE. Under these conditions, complex R2YE medium may be depleted of an essential nutrient. Sporulation in liquid R2YE was reduced drastically (by $>70 \%$ ) when proline was omitted from R2YE, and no sporulation was observed when $\mathrm{CaCl}_{2}$ was eliminated from $\mathrm{R} 2 \mathrm{YE}$.

None of the Streptomyces strains listed in Table 1 sporulated, or they did so very poorly, in complex liquid YED, LB, TSB or YEME media after $7 \mathrm{~d}$ of growth, suggesting that sporulation in complex medium R2YE could be induced by a nutritional depletion triggered by the high concentration of $\mathrm{Ca}^{2+}(20 \mathrm{mM})$ present in R2YE but not in the other media. Indeed, the sporulation of these five strains in complete R2YE medium was reduced progressively when increasing concentrations of EGTA (5-30 mM) were added, and no sporulation was observed in liquid R2YE supplemented with $40 \mathrm{~mm}$-EGTA. Similarly, phytic acid (10 mM) also inhibited sporulation in liquid R2YE. 
Table 3. Effects of calcium and phosphate on the sporulation of different Streptomyces strains in liquid medium

The results shown are means of three independent experiments.

\begin{tabular}{|c|c|c|c|c|}
\hline \multicolumn{2}{|c|}{$\begin{array}{c}\text { Concentration (mM) } \\
\text { in R2YE }\end{array}$} & \multicolumn{3}{|c|}{ Percentage sporulation of submerged culture } \\
\hline $\mathrm{CaCl}_{2}$ & $\mathrm{KH}_{2} \mathrm{PO}_{4}$ & S. griseus 10137 & S. griseus 3570 & S. acrimycini 2236 \\
\hline $5^{*}$ & 0 & 98 & 18 & 35 \\
\hline $5^{*}$ & 0.36 & 96 & 18 & 23 \\
\hline $5^{*}$ & 0.73 & 12 & 13 & 17 \\
\hline $5^{*}$ & 1.46 & 2 & 1 & 2 \\
\hline $5 \dagger$ & 3.67 & 0 & 0 & $0 \cdot 2$ \\
\hline $15 t$ & 3.67 & $0 \cdot 1$ & $0 \cdot 1$ & $0 \cdot 2$ \\
\hline $20 \dagger$ & 3.67 & $1 \cdot 3$ & 0.3 & 0.4 \\
\hline $25 \dagger$ & 3.67 & $5 \cdot 5$ & 4.9 & $5 \cdot 1$ \\
\hline $45 \dagger$ & 3.67 & 40 & 12 & $9 \cdot 6$ \\
\hline
\end{tabular}

\section{Calcium induction and phosphate inhibition of sporulation}

In order to study the effects of calcium and phosphate on the sporulation of Streptomyces in liquid medium the effect of $\mathrm{CaCl}_{2}$ addition to liquid R2YE was studied. S. griseus ATCC 10137, S. griseus JI 2212 and $S$. albus G sporulated almost uniformly ( $>95 \%$ ) after $3 \mathrm{~d}$ of growth in liquid R2YE, without $\mathrm{KH}_{2} \mathrm{PO}_{4}$ (normally R2YE is supplemented with $0.36 \mathrm{mM}-\mathrm{KH}_{2} \mathrm{PO}_{4}$ ) and with $5 \mathrm{mM}$ instead of $20 \mathrm{mM}-\mathrm{CaCl}_{2}$. The sporulation of $S$. griseus ATCC 10137 was progressively delayed and reduced when increasing concentrations of $\mathrm{KH}_{2} \mathrm{PO}_{4}$ were added, and no formation of submerged spores occurred in liquid R2YE $\left(5 \mathrm{mM}-\mathrm{CaCl}_{2}\right)$ supplemented with $3.67 \mathrm{mM}$ $\mathrm{KH}_{2} \mathrm{PO}_{4}$ after $6 \mathrm{~d}$ of growth. The phosphate inhibition of the sporulation was reversed by increasing the concentration of $\mathrm{CaCl}_{2}$ (Table 3). Calcium induction and phosphate inhibition of the sporulation were also observed for $S$. griseus IMRU 3570 and $S$. acrimycini JI 2236, although the sporulation efficiencies were low in the conditions used. S. albus $\mathrm{G}$ and $S$. griseus JI 2212 required a high level of phosphate $\left(>30 \mathrm{mM}-\mathrm{KH}_{2} \mathrm{PO}_{4}\right)$ to inhibit the sporulation process. Under these conditions, addition of a high concentration of $\mathrm{CaCl}_{2}(40-80 \mathrm{mM})$ did not reverse the inhibitory effect of phosphate and even seemed to have an additional inhibitory effect on sporulation, since thermosensitive swollen structures were formed.

\section{Sensitivity of aerial and submerged spores to moist heat}

The thermoresistance of spores formed in submerged cultures was compared to that of aerial spores and vegetative mycelium. Submerged spores from $S$. griseus IMRU 3570, S. griseus ATCC 10137, S. acrimycini JI 2236, S. griseus JI 2212 and $S$. albus $\mathrm{G}$ were as thermoresistant as aerial spores (after $60 \mathrm{~min}$ of heating at $55^{\circ} \mathrm{C}, 60-100 \%$ of the spores remained viable), while vegetative mycelium was very sensitive to heat (after $10 \mathrm{~min}$ of heating at $55^{\circ} \mathrm{C}$ all the mycelia were killed). Indeed, submerged spores of S. griseus ATCC 10137 were more resistant to heat than aerial spores under the conditions used. We chose the treatment time of $30 \mathrm{~min}$ for the following studies because after this period of heating at $55^{\circ} \mathrm{C}$ all the mycelia were killed and practically $100 \%$ of the submerged spores were viable. Fig. 1 shows the evolution of c.f.u. $\mathrm{ml}^{-1}$ in the absence of heating and after $30 \mathrm{~min}$ of heating at $55^{\circ} \mathrm{C}$ of the previous Streptomyces strains growing in MM + TES buffer (25 mM, pH 7.2) after nutritional downshift. The increased number of c.f.u. observed after $96 \mathrm{~h}$ of growth indicated that the mycelia were very fragmented; and the similar sporulation efficiencies observed with and without heating or by sonication showed that hyphal plating units were really short chains of spores. 


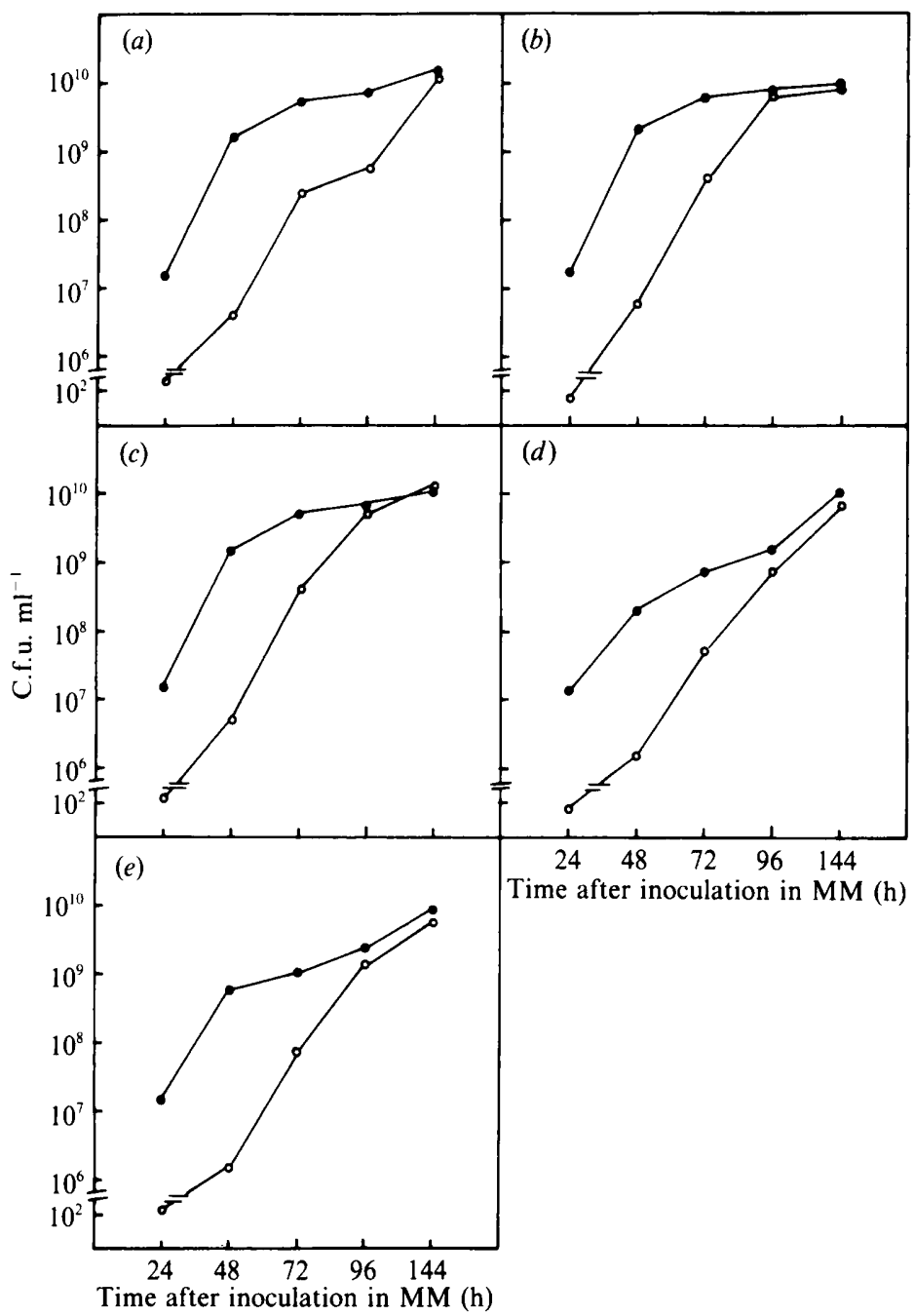

Fig. 1. Increase in c.f.u. $\mathrm{ml}^{-1}$ with time in the absence of heating (O) and after $30 \mathrm{~min}$ of heating at $55^{\circ} \mathrm{C}(\mathrm{O})$ in submerged cultures of $S$. griseus ATCC $10137(a), S$. griseus JI $2212(b), S$. albus G (c), $S$. acrimycini JI $2236(d)$ and $S$. griseus IMRU $3570(e)$. All the cultures were grown in liquid MM + TES buffer $(25 \mathrm{mM}, \mathrm{pH} \mathrm{7.2)}$ after nutritional downshift from liquid YED. Similar results were obtained when the Streptomyces strains were grown in liquid R2YE without nutritional downshift. The submerged cultures from the first $2 \mathrm{~d}$ were gently sonicated to give hyphae of about $15 \mu \mathrm{m}$. From the third day of growth it was not necessary to sonicate the cultures, because they mostly contained individual spores or short spore chains.

\section{Electron microscopy of submerged spores}

The results obtained by scanning electron microscopy confirmed the formation of spores observed by phase contrast microscopy. Fig. 2 shows scanning electron micrographs of submerged cultures of $S$. griseus ATCC 10137 (grown in R2YE), S. griseus JI 2212 (grown in MM + TES), $S$. albus G (grown in R2YE) and $S$. griseus IMRU 3570 (from MM + TES) after $6 \mathrm{~d}$ of growth. Submerged spores observed in MM after nutritional downshift remained largely as short spore chains whereas spores obtained from R2YE were mostly individual spores. Fig. 3 shows three steps of the differentiation process of S. acrimycini JI 2236 growing in liquid MM + TES after nutritional downshift. 

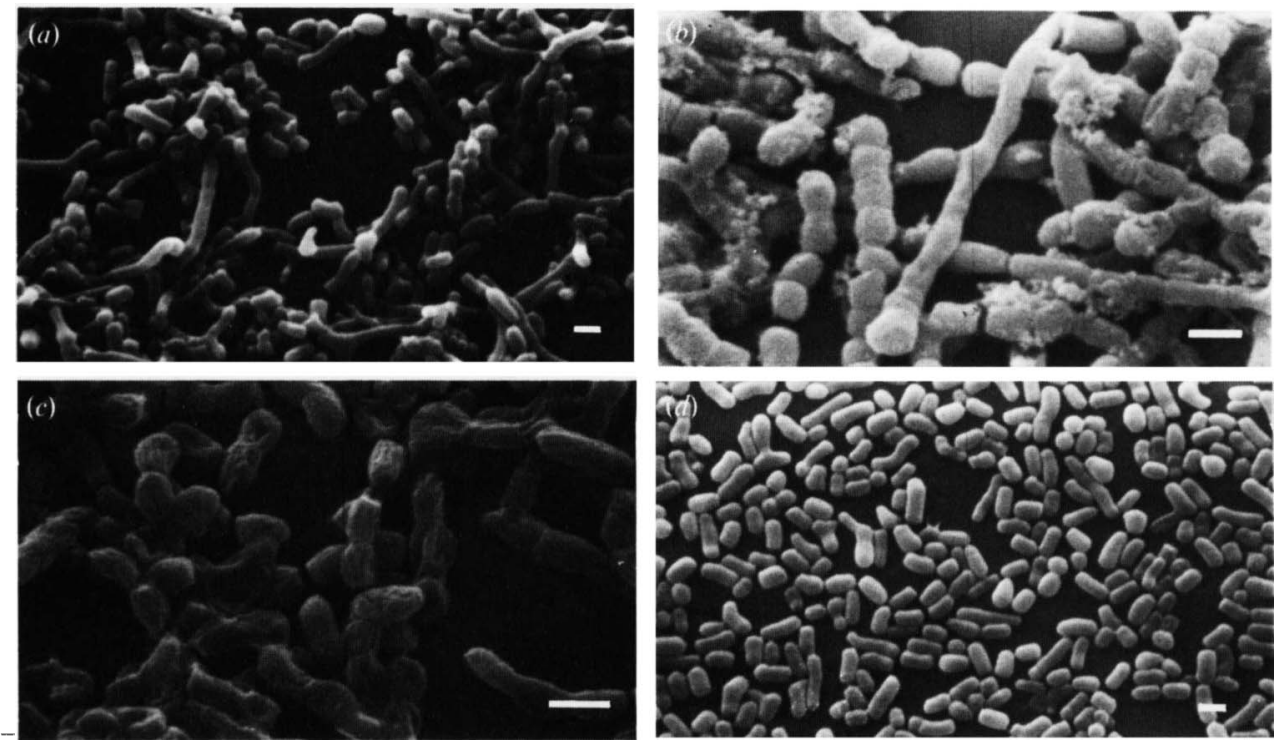

Fig. 2. Scanning electron micrographs of submerged spores of $S$. albus G from liquid R2YE (a), S. griseus IMRU 3570 from liquid MM + TES (b), S. griseus JI 2212 from liquid MM + TES (c) and S. griseus ATCC 10137 from liquid R2YE (d). Bars, $1 \mu \mathrm{m}$.
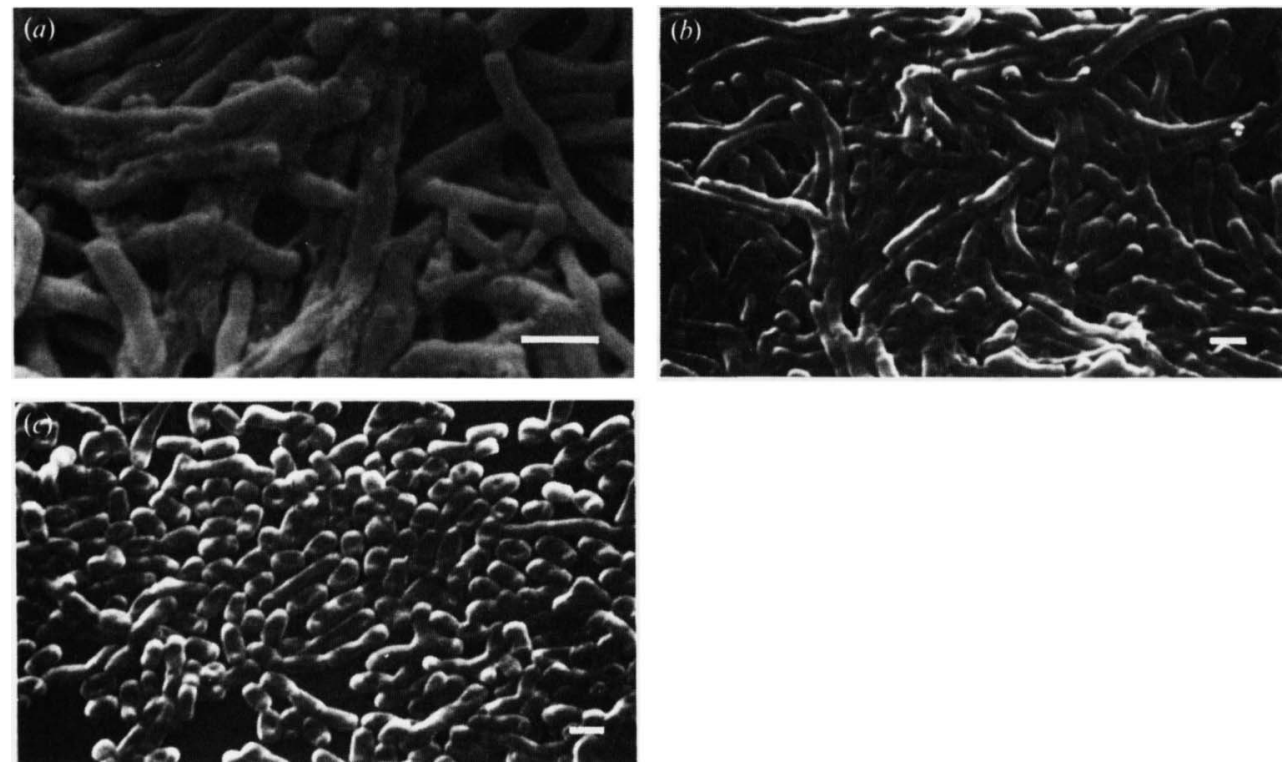

Fig. 3. Scanning electron micrographs showing the differentiation process of S. acrimycini JI 2236 in liquid MM + TES after $24 \mathrm{~h}(a), 50 \mathrm{~h}(b)$ and $90 \mathrm{~h}(c)$ of growth. Bars, $1 \mu \mathrm{m}$.

\section{Formation of spore-shaped bodies by S. lividans and S. coelicolor}

S. lividans JI 1326 and S. coelicolor JI 2280 did not sporulate in any of the conditions assayed. For these two strains, only $1-2 \%$ of formation of thermoresistant spores was observed in liquid R2YE ( $2 \mathrm{mM}^{-\mathrm{CaCl}}{ }_{2}$, without $\mathrm{KH}_{2} \mathrm{PO}_{4}$ ) after $5 \mathrm{~d}$ of growth. However, spore-shaped bodies were abundantly formed by both strains in liquid YED supplemented with $20 \mathrm{mM}-\mathrm{CaCl}_{2}$ and $40 \mathrm{~mm}$-proline after $70 \mathrm{~h}$ of growth (Fig. 4). Neither of these strains 'differentiated' in control 


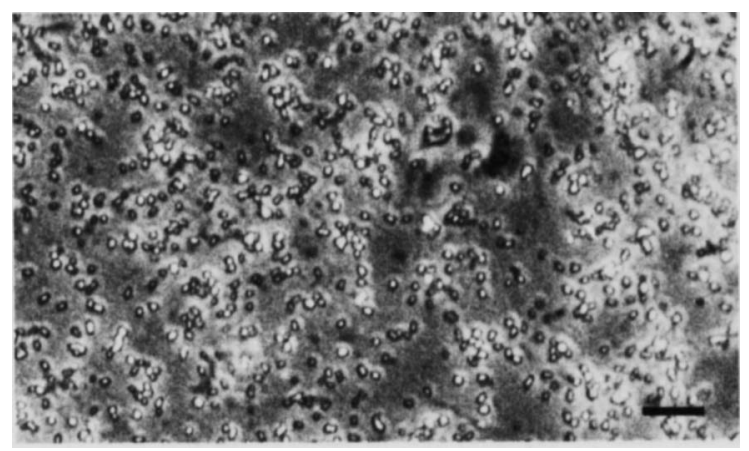

Fig. 4. Phase-contrast photomicrograph of spore-shaped bodies of S. lividans JI 1326 formed in liquid YED supplemented with $20 \mathrm{mM}-\mathrm{CaCl}_{2}$ and $40 \mathrm{mM}$-proline. Photograph taken after $72 \mathrm{~h}$ of growth. Bar, $5 \mu \mathrm{m}$.

flasks with YED or YED + 40 mM-proline after $6 \mathrm{~d}$ of growth, suggesting an effect of $\mathrm{Ca}^{2+}$ on this process. These spore-like bodies were also formed in a modified R2YE lacking sucrose and containing an increased proline concentration $(40 \mathrm{mM})$. These spore-shaped bodies were viable in hypotonic media, but were completely killed after $5 \mathrm{~min}$ of heating at $55^{\circ} \mathrm{C}$, in contrast with the thermoresistance of aerial spores from these two strains (more than $20 \%$ of survivors after $30 \mathrm{~min}$ of heating at $55^{\circ} \mathrm{C}$ ) and were not transformed by plasmid DNA. The formation of sporeshaped bodies by $S$. lividans and $S$. coelicolor in liquid YED $+20 \mathrm{~mm}-\mathrm{CaCl}_{2}+40 \mathrm{~mm}$-proline was also inhibited by the addition of $\geqslant 5 \mathrm{mM}$ of $\mathrm{KH}_{2} \mathrm{PO}_{4}$ or sodium phosphate buffer, $\mathrm{pH} 7 \cdot 4$.

Addition of very high concentrations of sodium phosphate buffer $(\geqslant 40 \mathrm{~mm})$ to modified YED or MM liquid media led to the formation of peculiar swollen structures more than $5 \mu \mathrm{m}$ in diameter by the ten Streptomyces strains listed in Table 1. These swollen bodies were formed after $24-30 \mathrm{~h}$ of growth, but were not viable and have not been studied in detail.

\section{DISCUSSION}

Studies on the molecular biology of differentiation in Streptomyces have been hampered by the difficulty in obtaining abundant sporulation in liquid medium. Most streptomycete strains do not sporulate in liquid culture (Ensign, 1978). Of the ten Streptomyces strains tested in this work, five formed aerial spores on solid medium and submerged spores in liquid medium. Electron microscopic studies have provided evidence that the spherical or elongated submerged culture units observed by phase contrast microscopy are indeed spores. In all cases, the aerial and submerged spores showed similar thermoresistance. Submerged spores of $S$. griseus ATCC 10137 were even more thermoresistant than aerial spores.

The sporulation process in liquid media takes place not only in MM + TES after nutritional downshift but also in rich medium containing a high $\mathrm{Ca}^{2+}$ concentration after incubation for 2-6 d. The efficiency of sporulation of these five strains was similar in siliconized flasks; indeed there was practically no growth on the flask walls and after 4 or $5 \mathrm{~d}$ of growth no clumps of hyphae formed and the remaining short fragments were spore chains. The reproducibility of the process was a common feature (only $4-6 \%$ of variation in ten independent experiments).

Sporulation of all the Streptomyces strains capable of sporulation in liquid R2YE was inhibited when $\mathrm{CaCl}_{2}$ was omitted from liquid $\mathrm{R} 2 \mathrm{YE}$. Uptake of $\mathrm{Ca}^{2+}$ ions is commonly known to play a role during sporulation in Bacillus (Mandelstam, 1976) and Streptomyces (Salas et al., 1983). A high concentration of $\mathrm{Ca}^{2+}$ may induce sporulation by trapping phosphate ions as insoluble calcium phosphate. Recently, Natsume et al. (1989) observed that $\mathrm{Ca}^{2+}$ regulated aerial mycelium formation in Streptomyces on solid media, and they also proposed that $\mathrm{Ca}^{2+}$ might lessen the intracellular concentration of phosphate. We observed that sporulation in liquid R2YE was dependent on the presence of $\mathrm{Ca}^{2+}$ in the medium and was reduced 
progressively by addition of increasing concentrations of chelating agents (EGTA or phytic acid).

Phosphate levels are critical for vegetative growth and for induction of secondary metabolism and differentiation (Martín, 1989). Production of nanaomycin and other antibiotics is stimulated by addition of phosphate-trapping agents to the fermentation (Masuma et al., 1986). We observed that sporulation was inhibited by the addition of phosphate to liquid R2YE, although the different Streptomyces strains showed different responses to the phosphate concentration. This inhibitory effect of phosphate was also observed in liquid minimal medium; however, it was less drastic, probably due to depletion of other nutrients. The inhibitory effect of phosphate was reversed by $\mathrm{Ca}^{2+}$ at low phosphate concentrations; at high phosphate concentrations, $\mathrm{Ca}^{2+}$ induction of sporulation was not observed. The presence of high concentrations of calcium and phosphate led to the formation of swollen structures, probably spores with altered cell walls, which were not thermoresistant.

There are several important differences between our results and the microcycle sporulation described by Koepsel \& Ensign (1984). Microcycle sporulation is based on the synchronous germination of spores followed by the arrest of germ tube growth which results in sporulation. Vegetative growth has to be limited for spores to form. In our system, extensive vegetative growth is allowed to occur followed by a nutritional downshift, which commits the cells to sporulation. Sporulation in submerged culture is not inhibited by glucose since sporulation of these strains occurred in liquid MM (55 mM-glucose) even when this medium was supplemented with additional glucose (up to $166 \mathrm{~mm}$ ). This contrasts with the results of Koepsel \& Ensign (1984), who reported that $1 \mathrm{~mm}$-glucose inhibits microcycle sporulation. Sporulation in liquid R2YE was however reduced when glucose was omitted from liquid R2YE (data not shown).

$S$. clavuligerus, $S$. lactamdurans and $S$. fradiae did not sporulate in the conditions used, and no further attempts were made to induce sporulation of these strains in liquid media. S. lividans and $S$. coelicolor, when grown in liquid YED supplemented with $\mathrm{Ca}^{2+}$ and proline, formed sporeshaped bodies. Aerial spores from these two strains were more sensitive to heat than aerial and submerged spores of the other strains tested, but were more thermoresistant than the sporeshaped bodies formed in submerged cultures. These bodies are viable and their formation responds similarly to that of the true submerged spores. Although the effect of different concentrations of calcium, phosphate, sucrose and proline added to R2YE medium were examined, no significant formation of thermoresistant submerged spores by $S$. lividans and $S$. coelicolor was observed. It is possible that the optimal concentrations of these compounds were not found, but the possibility that other different effectors are necessary to induce the sporulation of these strains cannot be excluded.

Although it is not still clear what is the intracellular signal which commits the cell to sporulation, we believe that the ratio between $\mathrm{Ca}^{2+}$ and phosphate or nucleotides may play an important role in the induction of the sporulation in submerged cultures. Ochi (1987) showed that the decrease in GTP content caused by the stringent response was correlated with spore formation in $S$. griseus. One possibility is that a high concentration of $\mathrm{Ca}^{2+}$ reduces the GTP pool and induces the differentiation process. This nutritional signal probably triggers a complex cascade of regulatory effects (Chater et al., 1988) similar to that proposed to control secondary metabolism (Beppu, 1986; Martín \& Liras, 1989).

\section{REFERENCES}

BEPPU, T. (1986). Pleiotropic regulatory mechanisms of secondary metabolism in Streptomyces. In Overproduction of Microbial Metabolites, pp. 165-181. Edited by Z. Vanek \& Z. Hostalek. Boston: Butterworths. CHATER, K. F. (1984). Morphological and physiological differentiation in Streptomyces. In Microbial Development, pp. 89-115. Edited by R. Losick \& L. Shapiro. Cold Spring Harbor, NY: Cold Spring Harbor Laboratory.
Chater, K. F., Lawlor, E. J., Mendez, C., Bruton, C. J., Davis, N. K., Plaskitt, K., Guthrie, E. P., Daly, B. L., Baylis, H. A. \& Vu Trong, K. (1988). Gene expression during Streptomyces development. In Biology of Actinomycetes '88 (Proceedings of Seventh International Symposium on Biology of Actinomycetes, Tokyo, Japan), pp. 64-70. Edited by Y. Okami, T. Beppu \& H. Ogawara. Tokyo: Japan Scientific Societies Press. 
ENSIGN, J. C. (1978). Formation, properties and germination of actinomycete spores. Annual Review of Microbiology 32, 185-219.

Gil, J. A., Naharro, G., Villanueva, J. R. \& MARTín, J. F. (1985). Characterization and regulation of $p$-aminobenzoic acid synthase from Streptomyces griseus. Journal of General Microbiology 131, 1279-1287.

HaRdisson, C. \& Manzanal, M. B. (1976). Ultrastructural studies of sporulation in Streptomyces. Journal of Bacteriology 127, 1443-1454.

HopwOOD, D. A. (1967). Genetic analysis and genome structure in Streptomyces coelicolor. Bacteriological Reviews 31, 373-403.

Hopwood, D. A., Wildermuth, H. \& Palmer, H. M. (1970). Mutants of Streptomyces coelicolor defective in sporulation. Journal of General Microbiology 61, 397-408.

Hopwood, D. A., BibB, M. J., Chater, K. F., Kieser, T., BRUTON, C. J., KiesER, H. M., LydiATE, D. J., SMith, C. P., WARD, J. M. \& SchrempF, H. (1985). Genetic Manipulation of Streptomyces. A Laboratory Manual. Norwich: John Innes Foundation.

KENDRICK, K. E. \& ENSIGN, J. C. (1983). Sporulation of Streptomyces griseus in submerged culture. Journal of Bacteriology 155, 357-366.

KOEPSEL, R. \& ENSIGN, J. C. (1984). Microcycle sporulation of Streptomyces viridochromogenes. Archives of Microbiology 149, 9-14.

Luengo, J. M., Dominguez, A., Cantoral, J. M. \& MARTín, J. F. (1986). Formation of bulges associated with penicillin production in high-producing strains of Penicillium chrysogenum. Current Microbiology 13, 203-207.

Mandelstam, J. (1976). Bacterial sporulation: a problem in the biochemistry and genetics of a primitive developmental system. Proceedings of the Royal Society B193, 89-106.
Martín, J. F. (1989). Molecular mechanisms for the control by phosphate of the biosynthesis of antibiotics and other secondary metabolites. In Regulation of Secondary Metabolism in Actinomycetes. Edited by S. Shapiro. Boca Raton, Fl.: CRC Press (in the Press).

Martín, J. F. \& LiRAS, P. (1989). Organization and expression of genes involved in the biosynthesis of antibiotics and other secondary metabolites. Annual Review of Microbiology 43 (in the Press).

Masuma, R., Tanaka, Y., Tanaka, H. \& Omura, S. (1986). Production of nanaomycin and other antibiotics by phosphate-depressed fermentation using phosphate-trapping agents. Journal of Antibiotics 39, 1557-1564.

MILleR, J. H. (1972). Experiments in Molecular Genetics, p. 433. Cold Spring Harbor, NY: Cold Spring Harbor Laboratory.

Natsume, M., Yasui, K. \& Marumo, S. (1989). Calcium ion regulates aerial mycelium formation in actinomycetes. Journal of Antibiotics 42, 440-447.

OCHI, K. (1987). Changes in nucleotide pools during sporulation of Streptomyces griseus in submerged culture. Journal of General Microbiology 133, 2787-2795.

Salas, J. A., Guijarro, J. A. \& Hardisson, C. (1983). High calcium content in Streptomyces spores and its release as an early event during spore germination. Journal of Bacteriology 155, 1316-1323.

Thompson, C. J., WARD, J. M. \& Hopwood, D. A. (1983). DNA cloning in Streptomyces: resistance genes from antibiotic-producing species. Nature, London 286, 525-527.

WILDERMUTH, H. \& HoPWOOD, D. A. (1970). Septation during sporulation in Streptomyces coelicolor. Journal of General Microbiology 60, 51-59. 